\title{
Lumped Parameter Modelling of Cavitating Orifice Flow in Hydraulic Systems
}

\author{
Junjie Zhou* - Jibin Hu - Chongbo Jing \\ Beijing Institute of Technology, National Key Laboratory of Vehicular Transmission, China
}

Gaseous cavitation is an important issue that introduces negative effects on the performance of hydraulic systems. The lumped parameter modelling approach is widely adopted in the research of hydraulic applications due to its quickness and convenience to apply at the system level. For this reason, a novel lumped parameter model of cavitating orifice flow based on a control volume concept is presented in this paper. In particular, a procedure of calibrating the unknown model coefficients is provided by using the computational fluid dynamic (CFD) method as well as test data. A test rig for studying cavitation in an external gear pump is set up with a variable orifice at the inlet port. The four coefficients in the CFD cavitation model is first identified by the measured mass flow rate through the test orifice; then the CFD simulated fluid field offers required information including the average air mass fraction in downstream region to determine the two coefficients of lumped parameter (LP) model. To further verify the calibrated models, another test at a different pump speed is carried out to compare it to the model prediction. Good matching with experiments justifies the proposed approach and the calibration procedure. Suggestions for future work include extending the approach to the study of hydraulic valves and high-speed pumps.

Keywords: gaseous cavitation; lumped parameter; orifice; hydraulic systems

Highlights

- This paper presents a novel lumped parameter model of cavitating orifice flow based on the control volume concept.

- In the new model, a generalized gas evolution equation is used to calculate the air fraction in the orifice.

- A procedure of calibrating the unknown model coefficients in the presented model is proposed.

- $\quad$ The calibrated model is verified by experiments.

\section{INTRODUCTION}

In hydraulic systems, air release has been considered to be the main reason of gaseous cavitation [1] and [2], which easily happens as the components are subject to low static pressure (air separation pressure). Particularly, due to the upstream side connecting to the oil reservoir, hydraulic orifices or restrictions in the supply system of open circuits, cavitation may be more easily induced [3]. In other cases, the large pressure drop produced by the narrow flow restrictions in hydraulic control valves or the insufficient flow in high-speed rotating hydraulic pumps also indicates a strong tendency of gaseous cavitation [4] and [5]. Nowadays, the bigger pressure ratio or higher shaft speed required by the increasing power density of systems brings a significant challenge to the modelling and designing on the new generation of hydraulic components. The adverse effects of air release including the reduction of flow capacity of hydrostatic units, severe fluid borne noise generation and structural erosion must be minimized in the entire system [6].

As part of the multi-flow subject in fluid dynamics, the cavitation problem has been broadly studied from the interphase mass transfer to various types of applications in recent decades. Significant numerical models of describing multidimensional cavitating flow have been proposed on the basis of the computational fluid dynamic (CFD) approach. Typical examples are given by the models by Singhal et al. [7] (also known as the "full cavitation model"), Zwart et al. [8] and Schnerr and Sauer [9], which are already implemented in commercial software such as ANSYS Fluent [10]. However, these models are very limited to simulate fluid power systems or complex pumps since many aspects which have a substantial impact on the unit performance are neglected, as done in the literature [5] and [11]. For this reason, the lumped parameter (LP) approach is often employed in fluid power research because it is effective, quick as well as robust for studying the dynamic features of hydraulic systems. Not only commercial software such as LMS, AMESim, DSHplus, and Easy 5 but also the advanced numerical models for positive displacement machines [12] and [13] have been developed under this methodology and been highly successful. Applying a homogenous flow method, several lumped parameter fluid models have been proposed by Imagine [14], by Gholizadeh et al. [15] and by Casoli et al. [16]. Researchers have developed a novel fluid model that takes the dynamic features of air release/absorption into account, specifically the one presented in [17]. This model is validated for predicting fluid properties 
in a closed control volume and further utilized in the study of outlet pressure oscillations in external gear pumps [6].

In this paper, the cavitating flow through hydraulic orifices is uniquely investigated with the LP approach based on control volumes in Section 2. A CFD model is derived referring to Zwart Model [8], including four empirical constants. Due to the unknown coefficients, Section 3 provides a procedure to calibrate the CFD model and LP model by comparing them with experimental results. Including a variable orifice at the pump inlet port, a test rig of studying cavitation in the hydraulic circuit is built. The measured mass flow rate through the orifice is first used to calibrate the CFD gaseous cavitation model and eventually with the calculated flow field, the coefficients in the LP model are determined. In Section 4, more applications are conducted to further verify the obtained coefficients and the proposed calibration method. Finally, the main conclusions of this work are outlined in Section 5.

\section{MATHEMATICAL MODELLING}

\subsection{Gaseous Cavitation in CFD Approach}

In addition to the generalized governing equations (continuity equation, Navier-Stokes equations, and turbulence equations) of describing the flow characteristics in the multi-dimensional fluid field, the vapour transport equation is introduced by researchers to specifically model the cavitation phenomenon in two-phase flow. The previous cavitation models are mainly developed on the basis of water evaporation and condensation [7] to [9]. The difference of existing models only lies in the formulation of describing the interphase mass transfer rates. However, they share the same theoretical basis: bubble dynamics.

Considering the gaseous cavitation (air release) in hydraulic oils, although the interphase mass transfer performs a different mechanism (air release and absorption in oil instead of evaporation and condensation), the gas bubble theory is still regarded to be valid. Therefore, the presented model closely refers to the one proposed by Zwart et al. [8]. Note here that the "gas" discussed in this paper indicates "air" if not specified.

The air volume fraction in the fluid mixture is governed by Eq. (1).

$$
\frac{\partial}{\partial t}\left(\alpha \rho_{\mathrm{G}}\right)+\nabla \cdot\left(\alpha \rho_{\mathrm{G}} \vec{V}\right)=R_{\mathrm{r}}-R_{\mathrm{a}}
$$

where $\alpha$ is the gas volume fraction; $\rho_{\mathrm{G}}$ is gas density; $\vec{V}$ is the gas phase velocity; $R_{\mathrm{r}}, R_{\mathrm{a}}$ are the mass transfer terms corresponding to the air release and absorption, respectively.

The Rayleigh-Plesset equation which describes the single bubble is written as [18]:

$$
\begin{gathered}
\Re_{\mathrm{b}} \frac{D^{2} \Re_{\mathrm{b}}}{D t^{2}}+\frac{3}{2}\left(\frac{D \Re_{\mathrm{b}}}{D t}\right)^{2}= \\
=\left(\frac{p_{\mathrm{b}}-p}{\rho_{\mathrm{L}}}\right)-\frac{4 v}{\Re_{\mathrm{b}}} \frac{D \Re_{\mathrm{b}}}{D t}-\frac{2 \sigma}{\rho_{\mathrm{L}} \Re_{\mathrm{b}}},
\end{gathered}
$$

where, $\Re_{\mathrm{b}}$ is bubble radius; $p_{\mathrm{b}}$ is bubble surface pressure, which is set as air separation pressure; $\rho_{\mathrm{L}}$ is liquid (oil) density.

Similarly, by neglecting the second-order term, the effects of surface tension and liquid viscosity, the Rayleigh-Plesset equation can be deduced as:

$$
\frac{D \Re_{\mathrm{b}}}{D t}=\sqrt{\frac{2}{3} \frac{p_{\mathrm{b}}-p}{\rho_{\mathrm{L}}}} .
$$

For simplicity, all the air bubbles in the fluid mixture are considered to be spheres of the same radius. By introducing similar empirical coefficients, the mass transfer terms in Eq. (1) can be given as:

$$
\begin{aligned}
& R_{\mathrm{r}}=C_{\mathrm{r}} \alpha_{\mathrm{nuc}} \frac{3(1-\alpha) \rho_{\mathrm{G}}}{\mathfrak{R}_{\mathrm{b}}} \sqrt{\frac{2}{3} \frac{p_{\mathrm{b}}-p}{\rho_{\mathrm{L}}}}, \\
& R_{\mathrm{a}}=C_{\mathrm{a}} \frac{3 \alpha \rho_{\mathrm{G}}}{\mathfrak{R}_{\mathrm{b}}} \sqrt{\frac{2}{3} \frac{p-p_{\mathrm{b}}}{\rho_{\mathrm{L}}}}
\end{aligned}
$$

where, besides the bubble radius $\mathfrak{R}_{\mathrm{b}}$, the air release coefficient $C_{\mathrm{r}}$, air absorption coefficient $C_{\mathrm{a}}$ and the nucleation site volume fraction $\alpha_{\text {nuc }}$ are unknown.

By comparing the simulation to the experimental data, Zwart et al. [8] proposed a set of values through the study of water vaporous cavitation. However, concerning hydraulic oils and the different mass transfer mechanism, the model coefficients may be different. Therefore, more work is necessary to confirm the suitable values of these four coefficients, hence extending the usability of the CFD cavitation model.

\subsection{Lumped Parameter Modeling Approach}

The lumped parameter approach for modelling hydraulic systems is based on control volumes (CV), in which fluid properties are taken as uniform. For our study, the main structure of a hydraulic orifice is illustrated in Fig. 1, including three CVs: the upstream 
region, the throat region $\left(\mathrm{CV}_{1}\right)$ and the downstream region $\left(\mathrm{CV}_{2}\right)$.

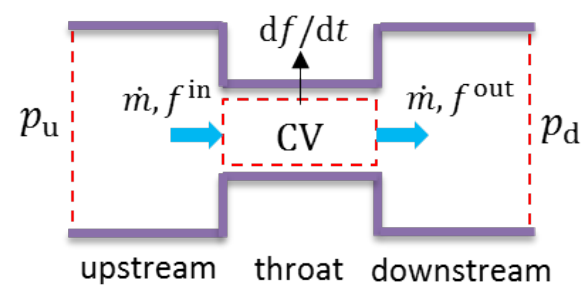

Fig. 1. Control volumes and flow exchanges in hydraulic orifice

The first significant step of modelling cavitating orifice flow is to predict the air content (mass fraction in this study) in each CV. This is easier for CFD method since all the information including air volume fraction distribution is calculated in the entire fluid field. To achieve this goal, a generalized formulation of governing the air mass fraction in the control volume has been presented in the authors' previous work [19], as written in Eq. (5).

$$
\frac{d f}{d t}=\left.\frac{d f}{d t}\right|_{\mathrm{IT}}+\frac{1}{m}\left(\sum \dot{m}_{\text {in }} f^{\text {in }}-\Sigma \dot{m}_{\text {out }} f^{\text {out }}\right)-\frac{f}{V} \frac{d V}{d t},
$$

where $f$ is the air mass fraction; $\left.\frac{d f}{d t}\right|_{\text {IT }}$ represents the internal transport effect; $m$ is the fluid mass in the control volume.

Regarding one open control volume connected to some other $\mathrm{CVs}$, the basic idea of this formulation comes from the fact that the mass balance of air in the CV includes two important effects: the internal mass transport - air release or absorption driven by the pressure difference and the external mass exchange interacting with adjacent CVs. In order to acquire air release/absorption rates in the air-oil system, in the author's previous work [17] a simplified equation is derived from "Full Cavitation Model" and validated for the cases of cyclic compression/expansion processes using a closed chamber. In this study, a similar equation is employed to evaluate the internal mass transport:

$$
\left.\frac{d f}{d t}\right|_{\mathrm{IT}}=z(1-f) \sqrt{p_{\mathrm{b}}-p}
$$

where $z$ also indicates a complex coefficient mainly related to geometric features of the studied structure and the operating condition.

Applying Eq. (5) and Eq. (6) on the cases of $\mathrm{CV}_{1}$ and $\mathrm{CV}_{2}$ of cavitating orifice shown in Fig. 1, since the volumes do not change, a set of equations of air content can be obtained:

$$
\left\{\begin{array}{l}
\frac{d f_{1}}{d t}=z_{1}\left(1-f_{1}\right) \sqrt{p_{\mathrm{b}}-p_{1}}+\frac{1}{m_{1}}\left(\dot{m} f_{1}^{\text {in }}-\dot{m} f_{1}^{\text {out }}\right) \\
\frac{d f_{2}}{d t}=z_{2}\left(1-f_{2}\right) \sqrt{p_{\mathrm{b}}-p_{2}}+\frac{1}{m_{2}}\left(\dot{m} f_{2}^{\text {in }}-\dot{m} f_{2}^{\text {out }}\right)
\end{array} .\right.
$$

Being focused on the steady-state study, it is reasonable to set the time-derivative of mass fractions of $\mathrm{CV}_{1}$ and $\mathrm{CV}_{2}$ as 0 . The mass flow rate through each connecting boundary should be the same due to mass conservation. The pressure in both regions is assumed to be approximately the downstream boundary pressure $p_{\mathrm{d}}$, and this point will be justified by the CFD simulation in Section 3.

In addition, due to that, air release mainly happens in $\mathrm{CV}_{1}$ and $\mathrm{CV}_{2}$, the flow coming from the upstream region is considered to be pure oil, meaning no air entrained in the entering flow of $\mathrm{CV}_{1}$. Furthermore, the mass fraction in outlet flow is supposed to equal to the value of source volume. Therefore, the following relations are also imposed.

$$
f_{1}^{\text {in }}=0, \quad f_{1}^{\text {out }}=f_{2}^{\text {in }}=f_{1}, \quad f_{2}^{\text {out }}=f_{2} .
$$

Then, Eq. (7) can be deduced as:

$$
\left\{\begin{array}{l}
z_{1} m_{1}\left(1-f_{1}\right) \sqrt{p_{\mathrm{b}}-p}=\dot{m} f_{1} \\
z_{2} m_{2}\left(1-f_{2}\right) \sqrt{p_{\mathrm{b}}-p}=\dot{m} f_{2}-\dot{m} f_{1}
\end{array} .\right.
$$

In Eq. (9), all the unknown variables $\left(m_{1}, m_{2}, f_{1}\right.$, $\left.f_{2}, \dot{m}\right)$ can be calculated from the CFD simulation results except the empirical constants $\left(z_{1}, z_{2}\right)$. Therefore, it is possible to calibrate their values by using simulation data once the CFD cavitation model is successfully standardized. In other words, the CFD model will be first calibrated by experimental data, and then it will help to further calibrate the lumped parameter model.

Suppose that the reasonable coefficients $\left(z_{1}, z_{2}\right)$ have been captured by the above procedure, there is still one problem in solving this equation (take the air mass fraction $f_{1}, f_{2}$ as unknowns) because the mass flow rate needs more consideration.

Fig. 2 illustrates the basic structure and boundary condition of the two-phase orifice flow, where, is the upstream pressure and $p_{\mathrm{u}}$ is the downstream pressure. The cross-sectional area of the throat is noted by $A$. 


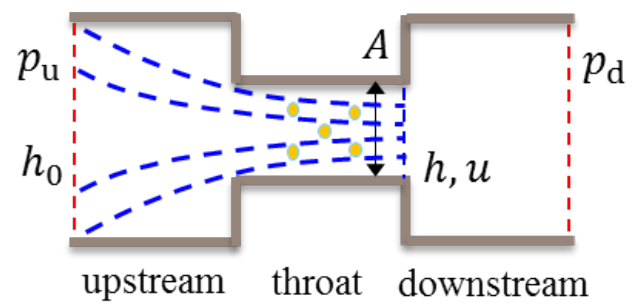

Fig. 2. Fluid field of two-phase orifice flow

Starting from the energy view, the specific enthalpy on both sides of fluid mixture is:

$$
h_{0}=h+\frac{u^{2}}{2}=f h_{\mathrm{G}}+(1-f) h_{\mathrm{L}}+\frac{u^{2}}{2},
$$

where $u$ indicates the velocity of fluid mixture; $h_{\mathrm{G}}$, $h_{\mathrm{L}}$ and $h$ are the enthalpy of gas, liquid, and mixture, respectively.

Then the mass flow rate through orifice is obtained as:

$$
\dot{m}=C_{\mathrm{q}} A \rho_{\mathrm{H}} u,
$$

where the density of the fluid mixture is evaluated by Eq. (12).

$$
\frac{1}{\rho_{\mathrm{H}}}=\frac{f}{\rho_{\mathrm{G}}}+\frac{1-f}{\rho_{\mathrm{L}}} .
$$

If the energy changes of gas and liquid are independent, one can derive:

$$
h_{0}-h=f\left(h_{\mathrm{G} 0}-h_{\mathrm{G}}\right)+(1-f)\left(h_{\mathrm{L} 0}-h_{\mathrm{L}}\right) .
$$

The pressure ratio is:

$$
k=\frac{p_{\mathrm{d}}}{p_{\mathrm{u}}} .
$$

The change of gas enthalpy is given as:

$$
h_{\mathrm{G} 0}-h_{\mathrm{G}}=c_{\mathrm{p}} T_{0}\left(1-\frac{T}{T_{0}}\right),
$$

where, $c_{\mathrm{p}}$ is specific heat of gas; $T_{0}$ is the constant temperature.

As the flow is considered to be the isentropic flow, the term $p^{1-\lambda} T^{\lambda}$ will be constant. Therefore, the following relation can be derived:

$$
\frac{T}{T_{0}}=\left(\frac{p_{\mathrm{d}}}{p_{\mathrm{u}}}\right)^{\frac{\lambda-1}{\lambda}} .
$$

Then, substituting Eq. (16) into Eq. (15), the first term in Eq. (13) becomes:

$$
f\left(h_{\mathrm{G} 0}-h_{\mathrm{G}}\right)=f c_{\mathrm{p}} T_{0}\left(1-k^{\frac{\lambda-1}{\lambda}}\right) .
$$

For the liquid phase, if the slight change of the oil temperature in other words the internal energy through the orifice is ignored, one can obtain:

$$
\begin{aligned}
(1-f)\left(h_{\mathrm{L} 0}-h_{\mathrm{L}}\right) & =(1-f)\left(\frac{p_{\mathrm{u}}}{\rho_{\mathrm{L}}}-\frac{p_{\mathrm{d}}}{\rho_{\mathrm{L}}}\right)= \\
& =(1-f) \frac{p_{\mathrm{u}}}{\rho_{\mathrm{L}}}(1-k) .
\end{aligned}
$$

Combining Eq. (11) to Eq. (18), the mass flow rate through the orifice is formulated as the function of air content as follows:

$$
\dot{m}=C_{\mathrm{q}} A \frac{\sqrt{B_{1}(f)\left(1-k^{\frac{\lambda-1}{\lambda}}\right)+B_{2}(f)(1-k)}}{B_{3}(f) k^{-\frac{1}{\lambda}}+B_{4}(f)},
$$

where

$$
\begin{aligned}
& B_{1}=2 f_{c_{\mathrm{p}}} T_{0}, \quad B_{2}=2(1-f) \frac{p_{\mathrm{u}}}{\rho_{\mathrm{L}}}, \\
& B_{3}=\frac{f}{\rho_{\mathrm{G} 0}}\left(\frac{p_{\mathrm{u}}}{p_{0}}\right)^{-1 / \lambda}, \quad B_{4}=\frac{1-f}{\rho_{\mathrm{L}}} .
\end{aligned}
$$

Thus far, it is evident that the mass flow relates to the gas mass fraction. Because the pressure ratio is known from the boundary condition, the mass flow rate only depends on $f$. Combining with Eq. (19), Eq. (9) is closed.

\section{CALIBRATION OF MODEL COEFFICIENTS}

\subsection{Experimental Setup}

A test rig is built to offer the necessary data to perform the parameter calibration. The experimental setup, illustrated by the diagram of Fig. 3, permits the measurements of steady-state flow rate and pressure. A variable orifice is installed to create a desired low pressure at the pump inlet pipe. This orifice can be operated to induce different low pressures or insufficient flows at the inlet port; meanwhile, the pressure is measured by P2. Another variable orifice is placed in outlet pipe serving as the pressure load. The main fluid parameters and equipment specifications are presented in the next table.

The test data used in model calibration are obtained at the operation condition of $1500 \mathrm{rpm}$ shaft speed, 100 bar outlet pressure. By adjusting the inlet orifice opening area at the same speed and load pressure, insufficient oil filling happens first, and then the downstream pressure (P2) starts to decrease. 
When the inlet pressure drops under air separation pressure (about the same as the atmosphere pressure), the air separates from the oil, hence inducing gaseous cavitation. Three cases are run, and all the data of inlet pressure, outlet flow rate, and even pressure oscillations are collected. It should be mentioned here that the mass flow rate was evaluated from the test data of Q1 since the oil density is known.

Table 1. Features of fluid and main elements of the apparatus

\begin{tabular}{|c|c|c|}
\hline Element & Type & Main features \\
\hline $\begin{array}{l}\text { Hydraulic } \\
\text { oil }\end{array}$ & $\begin{array}{l}\text { ISO VG } 46 \\
\text { mineral oil }\end{array}$ & $\begin{array}{l}\text { Density: } 840 \mathrm{~kg} / \mathrm{m}^{3} \text {, Operating temperature: } \\
298 \mathrm{~K} \text {; Air separation pressure: } 1.05 \mathrm{bar}\end{array}$ \\
\hline P2 & Strain gage & $\begin{array}{l}\text { WIKA®, Scale: } 0 \text { bar to } 40 \text { bar, } \\
0.25 \% \text { FS accuracy }\end{array}$ \\
\hline P4 & Strain gage & $\begin{array}{l}\text { WIKA } ® \text {, Scale } 0 \text { bar to } 40 \text { bar, } \\
0.25 \% \text { FS accuracy }\end{array}$ \\
\hline P3 & Piezoelectric & $\begin{array}{l}\text { KISTLER }{ }^{\circledR} \text {, Scale: } 0 \text { bar to } 1000 \text { bar, } 140 \\
\text { kHz Natural frequency, } 0.8 \% \text { FS accuracy }\end{array}$ \\
\hline Q1 & Flow meter & $\begin{array}{l}\text { VSE } ® \text { VS1, Scale } 0.05 \mathrm{I} / \mathrm{min} \text { to } 80 \mathrm{l} / \mathrm{min} \text {, } \\
0.3 \% \text { measured value accuracy }\end{array}$ \\
\hline
\end{tabular}

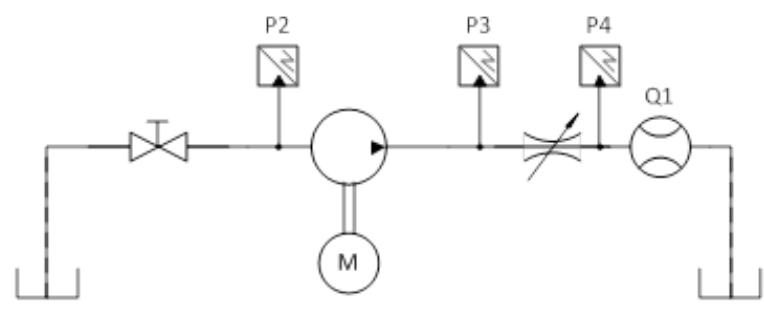

Fig. 3. Diagram of the external gear pump test system

\subsection{Calibration of Model Coefficients}

Due to the axisymmetric structure, the upper half area of the orifice is used as the $2 \mathrm{D}$ computational field, as shown in Fig. 4.

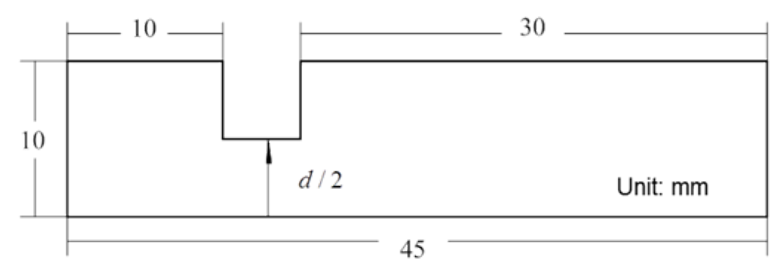

Fig. 4. Main dimensions of test orifice fluid field
In order to calibrate empirical coefficients in the CFD gaseous cavitation model, three parameter sets are carefully chosen based on the experience of previous research including Set A proposed by Zwart et al. [8], Set B proposed by Campo et al. [5] and Set $\mathrm{C}$ provided by the authors. All the values are shown in Table 2.

Table 2. Tested coefficient sets for the CFD cavitation model

\begin{tabular}{ccccc}
\hline Set & $\Re_{\mathrm{b}}[\mu \mathrm{m}]$ & $\alpha_{\text {nuc }}$ & $C_{\mathrm{r}}$ & $C_{\mathrm{a}}$ \\
\hline $\mathrm{A}$ & 1 & $5 \mathrm{e}-4$ & 0.4 & 0.001 \\
\hline B & 10 & 0.09 & 0.4 & 0.001 \\
\hline C & 10 & $5 \mathrm{e}-4$ & 0.09 & 0.01 \\
\hline
\end{tabular}

Simulations are run in an ANSYS Fluent environment with meshes generated from Gambit. In the CFD model, the standard k-epsilon turbulence model is employed. The problem is simplified as a 2D model as it is an "axisymmetric swirl". Fig. 5 shows the quadrilateral mesh of the fluid field, and it consists of 3400 cells in the present selection. The grid independence is checked by comparing the results between the presented grid with one encrypted grid which includes four times the number of cells. The relative error for all the three simulated cases is limited to $2.7 \%$; thereby the present mesh is chosen.

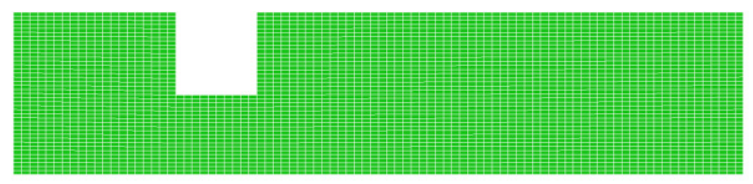

Fig. 5. The CFD mesh used in the fluid field

The outlet pressure used as the boundary condition in the CFD model is set according to the measured value of P2. Table 3 shows the operating parameters and simulated results obtained for each coefficient set tested. The pressures are given in absolute values in order to avoid negative numbers. Upstream pressure is calculated from the height of the tank position, and the throat diameter is estimated according to the valveopening area. From the comparison to test data, it is clear that Set A and Set B have a strong tendency to overestimate cavitation effects, which do not match

Table 3. Operating parameters and CFD simulation results

\begin{tabular}{cccccccccc}
\hline Case & $p_{\mathrm{u}}[\mathrm{bar}]$ & $p_{\mathrm{d}}[\mathrm{bar}]$ & $d[\mathrm{~mm}]$ & $Q_{\mathrm{t}}[\mathrm{L} / \mathrm{min}]$ & $\dot{m}_{\mathrm{t}}\left[\mathrm{kg} / \mathrm{m}^{3}\right]$ & $\dot{m}_{\mathrm{S}}-\mathrm{A}\left[\mathrm{kg} / \mathrm{m}^{3}\right]$ & $\dot{m}_{\mathrm{S}}-\mathrm{B}\left[\mathrm{kg} / \mathrm{m}^{3}\right]$ & $\dot{m}_{\mathrm{S}}-\mathrm{C}\left[\mathrm{kg} / \mathrm{m}^{3}\right]$ \\
\hline 1 & 1.05 & 0.94 & 9.8 & 16.3 & 0.2309 & 0.1674 & 0.1561 & 0.2484 \\
\hline 2 & 1.05 & 0.37 & 6.0 & 15.7 & 0.2198 & 0.1391 & 0.0811 & 0.2162 \\
\hline 3 & 1.05 & 0.28 & 5.4 & 13.4 & 0.1876 & 0.1213 & 0.0683 & 0.1848 \\
\hline
\end{tabular}



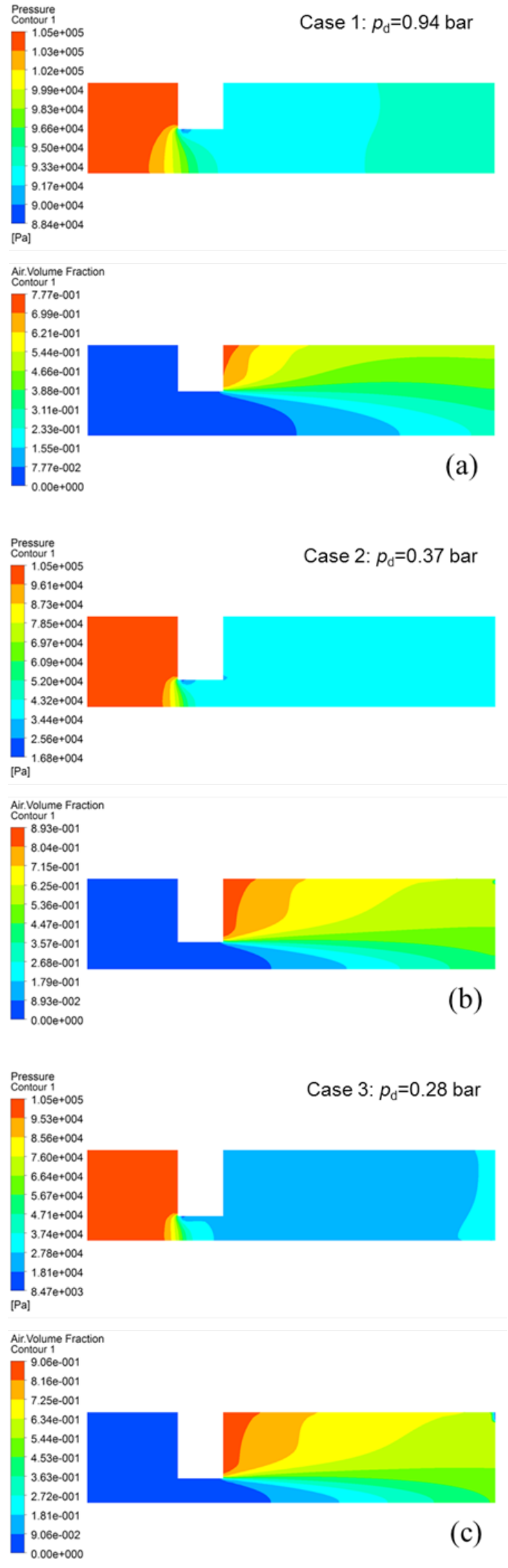

Fig. 6. Static pressure and air volume fraction in the fluid field; a) case 1, b) case 2 , and c) case 3 the measured mass flow rates. The result predicted by Set $\mathrm{C}$ seems more reasonable for all three cases. Therefore, the coefficients of the gaseous cavitation model in hydraulic oil are calibrated as the values of Set C.

Fig. 6 displays the static pressure and air volume fraction for each case predicted by the Set $\mathrm{C}$ cavitation model. It is easy to understand, with lower downstream pressure, more air appears in $\mathrm{CV}_{1}$ and $\mathrm{CV}_{2}$. In all cases, the pressure distributions in $\mathrm{CV}_{1}$ and $\mathrm{CV}_{2}$ are relatively close to $p_{\mathrm{d}}$, which confirms the assumption made in section 2.2. In addition, from the air volume fraction contours, the air content at the inlet of can be neglected as also done in Section 2.2.

From the CFD results, all the information, including average air mass fraction $\left(f_{1}, f_{2}\right)$, mass of fluid mixture $\left(m_{1}, m_{2}\right)$, which are needed to calibrate the lumped parameter model, are obtained in the post processing module. Then, depending on Eq. (9), the empirical coefficients $\left(z_{1}, z_{2}\right)$ in the LP model are solved. Table 4 lists the key variables and the obtained coefficient values in the LP cavitation model.

Table 4. Key variables and calculated coefficient values

\begin{tabular}{ccccc}
\hline Case & $f_{1}$ & $f_{2}$ & $z_{1}$ & $z_{2}$ \\
\hline 1 & $3.52 \mathrm{e}-5$ & $8.73 \mathrm{e}-4$ & $3.47 \mathrm{e}-4$ & $5.54 \mathrm{e}-4$ \\
\hline 2 & $5.31 \mathrm{e}-5$ & $19.4 \mathrm{e}-4$ & $3.80 \mathrm{e}-4$ & $5.47 \mathrm{e}-4$ \\
\hline 3 & $5.24 \mathrm{e}-5$ & $21.9 \mathrm{e}-4$ & $3.74 \mathrm{e}-4$ & $5.68 \mathrm{e}-4$ \\
\hline
\end{tabular}

In Table 4, due to the slight difference observed on the quantity of and, the LP model coefficients can be regarded as constant for the given orifice structure, although they may differ more for other orifices. From this point, the LP model is determined with the coefficients set as $z_{1}=3.6 \mathrm{e}-4$ and $z_{2}=5.6 \mathrm{e}-4$. Hence, the LP model will be applicable for other situation, because both the air mass fraction in $\mathrm{CV}_{1}, \mathrm{CV}_{2}$, and the mass flow rate passing the orifice can be obtained by solving Eq. (9) and Eq. (19) simultaneously.

\section{MODEL APPLICATION}

In order to further check the ability and applicability of the developed CFD and LP cavitation models, the tested pump is run at another shaft speed (1000 rpm) with four different opening positions of the inlet orifice. Using the proposed model coefficients, the mass flow rates predicted by both methods are compared to measured data, as depicted in Fig. 7.

From Fig. 7, it can be seen that the simulation results from both CFD model and LP model provide acceptable accuracy on predicting the mass flow rate, 
although they are not able to depict all measured aspects. Therefore, the calibrated coefficients are convincing and, more importantly, the proposed procedure of model calibration, particularly for the lumped parameter modelling approach, is justified. It is worth mentioning, although this method is built in terms of the employed orifice structure, it can be extended to other geometric configurations, such as various types of hydraulic valves.

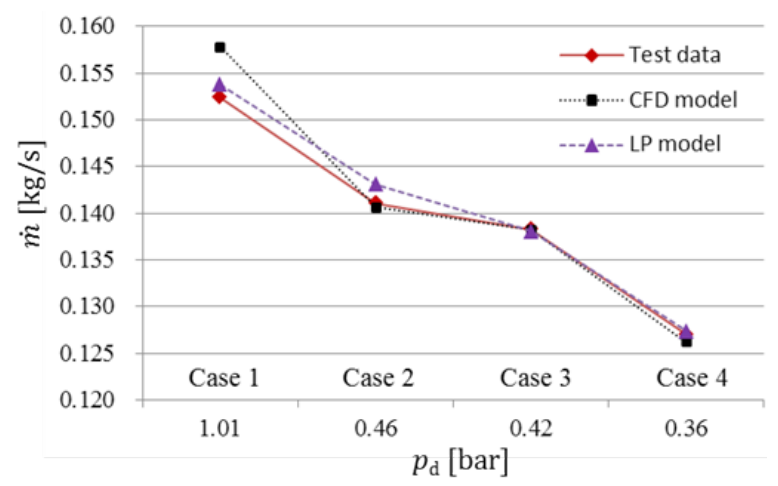

Fig. 7. Measured and predicted mass flow rates from CFD model and LP model at $1000 \mathrm{rpm}$ shaft speed

\section{CONCLUDING REMARKS}

This paper presents a novel model for predicting gaseous cavitation in hydraulic orifices. By simplifying the orifice as three connected control volumes, the cavitating flow is described by using the lumped parameter modelling approach. In order to calibrate the model coefficients in LP model, the orifice flow is also studied with the popular CFD method because the CFD model is easy to compare with the real test. An experimental apparatus of testing cavitation in hydraulic pump circuit is built, where a variable orifice is placed at the inlet line to induce low pressure.

As the procedure of model calibration, the measured mass flow rate through the orifice at three downstream pressures is first used to calibrate the four coefficients in CFD model. After choosing the suitable values, the simulated fluid field from Fluent is captured to further calculate the required parameters of demarcating the LP cavitation model. Then, the obtained empirical coefficients in both approaches are employed in the simulation of other operating conditions with different pump speeds. The agreement with experimental data shows good potentials of the proposed lumped parameter cavitation model, which is considered more suitable for cavitation study happening in hydraulic systems.
The success of this research can drive future work on the study of gaseous cavitation in hydraulic control valves or high-speed pumps.

\section{ACKNOWLEDGEMENTS}

This research is funded by National Science Foundation of China (Grant No. 51505030).

\section{NOMENCLATURES}

$A$ cross-sectional area, [ $\left.\mathrm{m}^{2}\right]$

$B_{1}, B_{2}, B_{3}, B_{4}$ parameters for calculating mass flow rate

$C_{\mathrm{q}}$ orifice flow coefficient

$C_{\mathrm{a}}$ air release coefficient

$C_{\mathrm{r}}$ air absorption coefficient

$Q$ flow rate, $[\mathrm{L} / \mathrm{min}]$

$R_{\mathrm{a}}$ mass transfer due to air release

$R_{\mathrm{r}}$ mass transfer due to air absorption

$T_{0}$ constant temperature, $[\mathrm{K}]$

$V$ volume, $\left[\mathrm{m}^{3}\right]$

$c_{\mathrm{p}}$ specific heat, $[\mathrm{J} /(\mathrm{kg} \cdot \mathrm{K})]$

$d$ diameter, $[\mathrm{m}]$

$f$ mass fraction of air

$h \quad$ specific enthalpy of fluid mixture, $[\mathrm{J} / \mathrm{kg}]$

$h_{0}$ initial specific enthalpy of fluid mixture, $[\mathrm{J} / \mathrm{kg}]$

$m$ mass, [kg]

$\dot{m}$ mass flow rate, $[\mathrm{kg} / \mathrm{s}]$

$\dot{m}_{\mathrm{t}}$ theoretical mass flow rate, $[\mathrm{kg} / \mathrm{s}]$

$\dot{m}_{\mathrm{s}}$ simulated mass flow rate, $[\mathrm{kg} / \mathrm{s}]$

$k$ pressure ratio

$p$ pressure, [bar]

$p_{\mathrm{b}} \quad$ air separation pressure, [bar]

$t$ time, [s]

$u$ velocity, $[\mathrm{m} / \mathrm{s}]$

$z$ coefficients in LP model

$\Re_{\mathrm{b}}$ bubble radius, [m]

$\alpha$ volume fraction

$\alpha_{\text {nuc }}$ nucleation site volume fraction

$\rho$ density, $\left[\mathrm{kg} / \mathrm{m}^{2}\right]$

$\lambda$ polytrophic index of gas

$\sigma$ surface tension,

$v \quad$ kinematic viscosity, $\left[\mathrm{m}^{2} / \mathrm{s}\right]$

\section{Subscripts}

IT internal transport

$\mathrm{G}$ gas (air)

$\mathrm{G}_{0}$ initial state of gas (air)

$\mathrm{L}$ liquid

$\mathrm{L}_{0}$ initial state of liquid

$\mathrm{H}$ fluid mixture

in inlet port 
out outlet port

u upstream

d downstream

$\mathrm{t}$ test data

s simulation data

0 initial condition

1 control volume 1

2 control volume 2

\section{REFERENCES}

[1] Wylie, E.M., Streeter, V.L. (1978). Fluid Transient, Michigan University Press, Ann Arbor.

[2] Gholizadeh, H., Burton, R., Schoenau, G. (2011). Fluid bulk modulus: a literature survey. International Journal of Fluid Power, vol. 12, no. 3, p. 5- 16, Dol:10.1080/14399776.2011 .10781033.

[3] Vacca, A., Klop, R., Ivantysynova, M. (2010). A numerical approach for the evaluation of the effects of air release and vapor cavitation on effective flow rate of axial piston machines. International Journal of Fluid Power, vol. 11, no. 1, p. 33-46, DOl:10.1080/14399776.2010.10780996.

[4] Wiggert, D.C., Sundquist, M.J. (1979). The effect of gaseous cavitation on fluid transients. ASME Journal of Fluids Engineering, vol. 101, no. 1, p. 79-86, DOI:10.1115/1.3448739.

[5] del Campo, D., Castilla, R., Raush, G.A., Gamez Montero, P.J., Codina, E. (2012). Numerical analysis of external gear pumps including cavitation. ASME Journal of Fluids Engineering, vol. 134, no. 8, article 081105, Dol:10.1115/1.4007106.

[6] Zhou, J., Vacca, A., Casoli, P., Lettini, A. (2014). Investigation of the Impact of Oil Aeration on Outlet Flow Oscillations in External Gear Pumps. International Fluid Power Expo, Las Vegas.

[7] Singhal, A.K., Athavale, M.M., Li. H.Y., Jiang, Y. (2002). Mathematical Basis and Validation of the Full Cavitation Model. ASME Journal of Fluids Engineering, vol. 124, no. 3 p. 617-624, D0I:10.1115/1.1486223.
[8] Zwart, P.J., Gerber, A.G., Belamri, T. (2004). A two-phase flow model for predicting cavitation dynamics. Proceedings of the $5^{\text {th }}$ International Conference on Multiphase Flow, Yokohama.

[9] Schnerr, G.H., Sauer, J. (2001). Physical and numerical modeling of unsteady cavitation dynamics. $4^{\text {th }}$ International Conference on Multiphase Flow, New Orleans.

[10] ANSYS FLUENT 12.0 (2009). Theory Guide - 16.7.4 Cavitation Models, Ansys, Canonsburg.

[11] Saxena, D. (2008). CFD Modeling of Cavitation in Axial Piston Pump. Purdue University, West Lafayette.

[12] Vacca, A., Guidetti, M. (2011). Modelling and experimental validation of external spur gear machines for fluid power applications. Simulation and Modeling Practice and Theory, vol. 19, no. 9, p. 2007-2031, Dol:10.1016/j. simpat.2011.05.009.

[13] Pelosi, M., Ivantysynova, M. (2011). The influence of pressure and thermal deformation on the piston/cylinder interface film thickness. Proceedings of the 52nd National Conference on Fluid Power, Las Vegas.

[14] IMAGINE S.A. (2007). HYD Advanced Fluid Properties, Technical Bulletin, no. 117, Rev7.

[15] Gholizadeh, H., Burton, R., Schoenau, G. (2012). Fluid bulk modulus: comparison of low pressure models. International Journal of Fluid Power, vol. 13, no. 1, p. 7-16, Dol:10.1080/14 399776.2012.10781042.

[16] Casoli, P., Vacca, A., Franzoni, G., Berta, G.L. (2006). Modeling of fluid properties in hydraulic positive displacement machines. Simulation Modeling Practice and Theory, vol. 14, no. 8, p. 1059-1072, Dol:10.1016/j.simpat.2006.09.006.

[17] Zhou, J., Vacca, A., Manhartsgruber, B. (2013). A novel approach for the prediction of dynamic features of air release and absorption in hydraulic oils. ASME Journal of Fluids Engineering, vol. 135, no. 9, article 091305, Dol:10.1115/1.4024864.

[18] Brennen, C.E. (1995). Cavitation and Bubble Dynamics, Oxford University Press, Oxford.

[19] Zhou, J., Vacca, A., Casoli, P. (2014). A novel approach for predicting the operation of external gear pumps under cavitating conditions. Simulation Modelling Practice and Theory, vol. 45, p. 35-49, D0l:10.1016/j.simpat.2014.03.009. 